九州大学学術情報リポジトリ

Kyushu University Institutional Repository

\title{
Effects of a Large Dose of Ecdysteroid on Development of Ovary in Bombyx Pupae
}

Hamada, Nobuyuki

Laboratory of Sericultural Chemistry, Faculty of Agriculture, Kyushu Iiniversity

Koga, Katsumi

Laboratory of Sericulture, Faculty of Agriculture, Kyushu University

Hayashi, Katsuya

Laboratory of Sericultural Chemistry, Faculty of Agriculture, Kyushu Iiniversity

https://doi.org/10.5109/23776

出版情報：九州大学大学院農学研究院紀要. 28 (1)，pp.23-30，1983-09. Kyushu University バージョン：

権利関係 : 


\title{
Effects of a Large Dose of Ecdysteroid on Development of Ovary in Bombyx Pupae
}

\author{
Nobuyuki Hamada*, Katsumi Koga† and Katsuya Hayashi \\ Laboratory of Sericultural Chemistry, Faculty of Agriculture, \\ Kyushu University 46-02, Fukuoka 812 \\ (Received January 29, 1983)
}

\begin{abstract}
Administration of $100 \mu \mathrm{g}$ 20-hydroxyecdysone into a female Bombyx pupa at day 2 retarded its adult emergence by up to 8 days. The hormone treatment caused a significant delay in weight increase of the ovary. However, the ovary weight reached a normal level after the elongated pupal period. The animals thus treated deposited fertilized eggs, which were heavier and larger than normal eggs. These results suggest that the high dose of exogenous hormone perturbed the ovarian development, but this perturbation was compensated by the elongation of developing time of ovaries.
\end{abstract}

\section{INTRODUCTION}

A hormone is usually effective in trace amounts upon its target organs and a high concentration of hormone is usually regarded as harmful to biological processes. However, insect pupae often exibit very high titre of the 'molting' hormone, ecdysteroid. The titre sometimes reaches a level of $10^{-6}$ $M$, which is one or two orders of magnitude higher than the 'physiological' concentrations of ecdysteroid estimated from the results of the induction of chromosomal puffs and of morphogenesis of imaginal discs (cf., e.g. Ashburner, 1973; Hanaoka and Ohnishi, 1974; Mandaron, 1973). It has been reported that tanning or ecdysis of integuments cultured in vitro requires ecdysteroid at a level of $10^{-5} \mathrm{M}$ (Marks, 1970). However, the role of high titre of the pupal hormone is uncertain at present.

Injection of high doses of various kinds of ecdysteroids is harmful to the silkmoth pupae that are diapausing due to the lack of ecdysteroid, bringing about adults with partial pupal cuticles (metathetely). However, once the normal adult development is commenced by administration of an appropriate dose of the hormone, readministration of large amounts of ecdysteroids seems no more harmful (Williams, 1968). Developing pupae may be resistant to high concentrations of external ecdysteroids. Moreover, injection of 20 -hydroxyecdysone (5 $\mu \mathrm{g}$ per animal) at day 4 into developing Bombyx pupae caused an increase in accumulation of yolk protein during oogenesis (Takei et al.,

Present adress: * Department of Virology, Kurume University School of Medicine, Kurume 830-91, and + Laboratory of Sericulture, Faculty of Agriculture, Kyushu University 46-01, Fukuoka 812. 
1978). As an attempt to search the mechanisms which make the pupal system resistant to hyperecdysonism and to study the role of the large concentration of pupal ecdysteroid, we injected various doses of 20-hydroxyecdysone into female Bombyx pupae and observed the effects. The present paper describes that the pupae which received the hormone at a dose as high as $100 \mu \mathrm{g}$ per animal at day 2 after larval-pupal ecdysis delay in adult emergence and produce eggs larger and heavier than normal. Application of this excess dose of hormone was also intended to inquire how a developing system responds toward external perturbation.

\section{MATERIALS AND METHODS}

\section{Materials}

Two hybrid races, N124 x Cl24 and N122 x C115, were used. Ovaries were dissected from pupae on a wax plate immersed in physiological saline, freed of sticking fat bodies and tracheae with forceps, and transferred onto slightly wet filter paper. After several seconds the ovaries were weighed in vials. Some series of samples were then dried thoroughly at $80^{\circ} \mathrm{C}$ and weighed again. The difference in weight before and after drying was taken as the water content of the ovaries.

\section{Injections of hormones}

At day 2 of pupal age, when the titre of endogenous ecdysteroid was at its maximum (Hanaoka and Ohnishi, 1974), 1 to $100 \mu \mathrm{g}$ per individual of 20 . hyroxyecdysone (Rhoto Pharmaceutical Co. Ltd, Osaka) in $10 \mu 110 \%$ ethanol was injected into female pupae with glass needles. Juvenile hormone (C-18, Eco-Chemical Intermediates, Cambridge) in $10 \mu$ peanut oil was similarly administered. Sometimes the ecdysteroid was injected at day 8 instead of day 2. Controls were given with ethanol or peanut oil only. 'Normal' animals received no operation.

\section{Investigation of weight, number and size of deposited eggs}

Freshly emerged moths were copulated for $6 \mathrm{~h}$ and allowed to oviposit onto filter paper under cover for several days. After counting the number of deposited eggs, many of them were detached from filter paper at random, weighed and measured for witdth and length by use of a Nikon Shadowgraph at a lo-fold scale. The product of the width and the length was taken to indicate the egg size. The rest of the eggs were cooled at $4^{\circ} \mathrm{C}$ from day 2 post-oviposition until 3 months in order to break diapause. They hatched after 11 days at $25^{\circ} \mathrm{C}$.

\section{RESULTS}

The length of time required for newly ecdysed pupae to complete adult development was almost 10 to 12 days for normal pupae, control pupae and those which received $1 \mu \mathrm{g}$ of 20 -hydroxyecdysone at day 2 of pupal stage (Fig. 


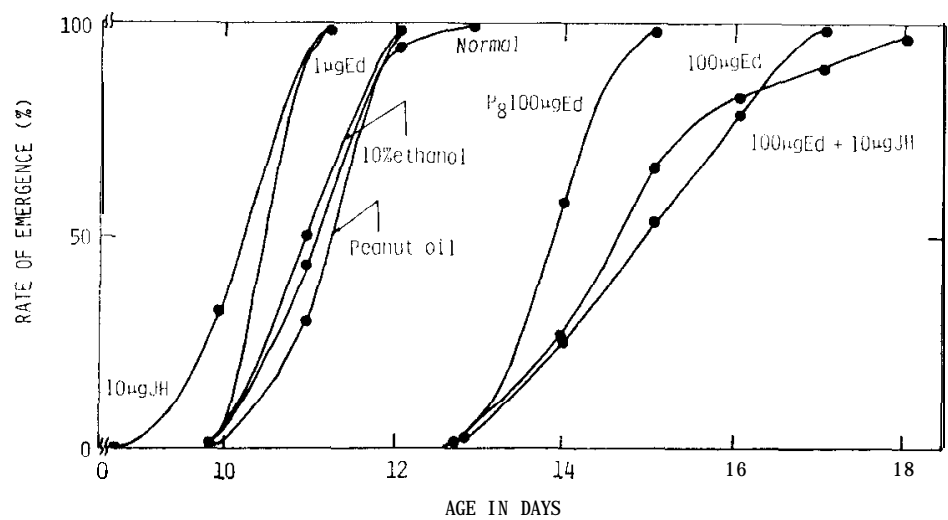

Fig. 1. Effects of 20-hydroxyecdysone (Ed) and C-18 juvenile hormone $(\mathrm{JH})$ on the date of emergence. The abscissa shows the days after larvalpupal ecdysis. The hormone was injected usually at day 2 or sometimes at day $8\left(\mathrm{P}_{8}\right)$. The dose (per pupa) of the hormone was specified beside each trace. For each dose 23 pupae were used. For 'normal', see Methods. Data with N $122 \times \mathrm{C} 115$ are seen. N $124 \times$ C 124 gave similar results.

1). This was also the case for $10 \mu \mathrm{g}$ dose of the same hormone (not shown). When $100 \mu \mathrm{g}$ of the ecdysteroid was given at day 2 , the first imago appeared at day 13 and the last imago appeared at day 18; thus adult emergence was up to 8 days later than normal. Day- 8 administration of $100 \mu \mathrm{g}$ of the ecdysteroid also retarded emergence but gave a smaller interval than day- 2 administration. Juvenile hormone $(\mathrm{JH})$ treatment $(10 \mu \mathrm{g})$ at day 2 quickend emergence by one day. This effect of $\mathrm{JH}$ was diminished by $100 \mu \mathrm{g} 20$-hydroxyecdysone injected simultaneously. When $1 \mathrm{mg}$ of 20 -hydroxyecysone was administered, the pupae died within a few days.

Fig. 2 shows the time course of changes in wet and dry weight of ovaries. The hormone treatment did not seem to affect the weight at least until day 6. At day 8, slight but statistically significant retardation in increase of the wet and dry weight was observed in the case of $100 \mu \mathrm{g}$ ecdysteroid. The weight at this day apparently depended upon the hormone dose. This was more clearly seen when the dry weight of the ovary was replotted against the hormone dose (Fig. 3).

The number of eggs deposited after mating (Fig. 4) seemed to be reduced due to $100 \mu \mathrm{g}$ ecdysteroid, although the difference was not significant. Moreover, ecdysteroid injection made the deviation of egg number smaller than normal (Fig. 4).

As shown in Fig. 5, the average weight of freshly deposited eggs seemed to be increased by administration of $100 \mu \mathrm{g}$ ecdysteroid at day 2 or 8 , but apparently decreased by JH injection at day 2 .

The animals treated with $100 \mu \mathrm{g}$ hormone at day 2 gave a wide distribution of the 'size' (see Methods) of deposited eggs compared to normal and other cases (Fig. 6). It is remarkable that many large-sized eggs were pro- 


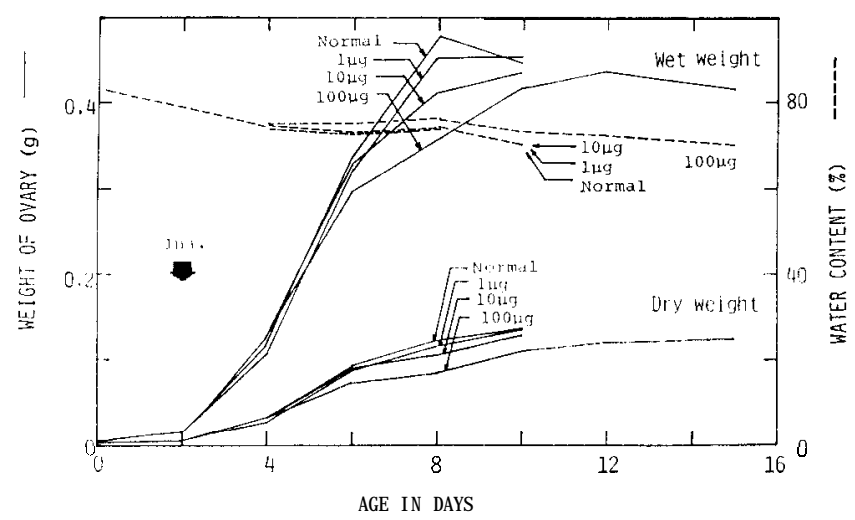

Fig. 2. Effects of 20-hydroxyecdysone on the weight of ovary during pupal stage. For abscissa, see Fig. 1. The hormone was injected into pupae ( $\mathrm{N} 124 \times \mathrm{C} 124)$ at day 2 at the dose (per pupa) specified in the figure. For each dose 15 pupae were used. Results are expressed in mean ovarian weight per pupa. For 'normal', see Methods. At day 8, the wet or dry weight for the $100-\mu$ g hormone sample was significantly smaller than the other samples ( $\mathrm{p}<0.05)$

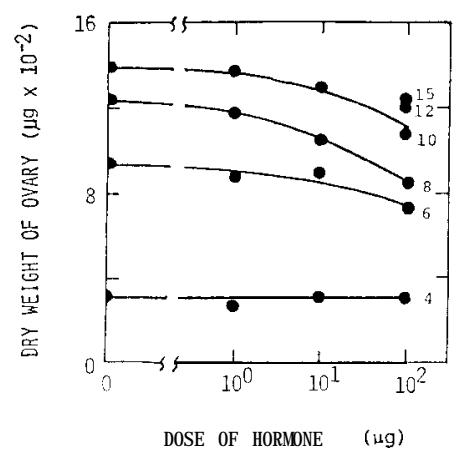

Fig. 3. Dry weight of ovary as a function of the dose of 20-hydroxyecdyssone (Ed) injected at day 2. The numerical numbers 4-15 are the age of pupae when the ovaries were weighed. Dose zero means control. Data were replotted from Fig. 2.

duced by $100 \mu \mathrm{g}$ hormone given at day 2 ; this makes the mean size of the eggs significantly larger compared to control (Fig. 7). A shoulder toward the large size was seen in the size distribution pattern when $100 \mu \mathrm{g}$ hormone was given at day 8 (Fig. 6). JH reduced the size of eggs significantly (Figs. 6 and 7).

The eggs deposited from the hormone treated animals were hatchable after break of diapause (see Methods). The average weight per eggshell remnant after hatching did not seem to be affected severely by the hormone treatment (Table 1). In the case of $100 \mu \mathrm{g}$ ecdysteroid the value was $83 \%$ of 


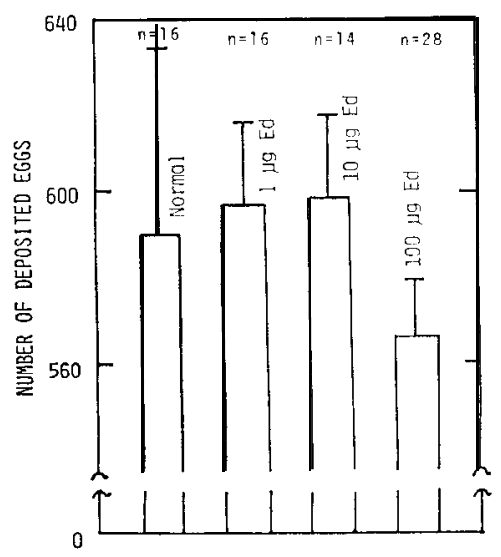

Fig. 4. Effects of 20-hydroxyecdysone (Ed) on the number of deposited eggs. Ed was injected into pupae $(\mathrm{N} 124 \times \mathrm{C} 124)$ at day 2 at the dose (per pupa) indicated in the figure. For each dose 14 to 28 pupae were used as indicated on top. Each bar represents the mean number of deposited eggs per pupa with a 95\% confidence interval. For 'normal', see Methods.

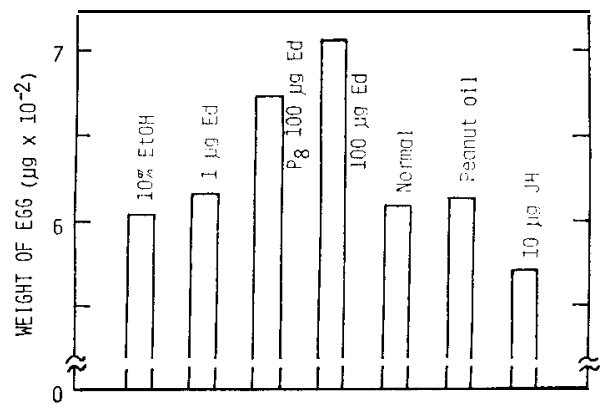

Fig. 5. Effects of 20-hydroxyecdysone (Ed) and C-18 juvenile hormone $\mathrm{JH})$ on the weight of deposited eggs. The hormone was injected into pupae (N $122 \times \mathrm{C} 115)$ at day 2 at the dose (per pupa) indicated in the figure. For each measurement 500 eggs were taken randomly out of a pool from 23 moths. They were weighed at once and the average weight per egg was obtained by division. For other details, see Figs. 1 and 2.

control and $92 \%$ of normal. The eggshell layer is partly ingested by the larva during hatching, and weighing the eggshell leftovers is an indirect measure for chorion proteins. We infer that the final amounts of accumulated chorion proteins in the hormone treated pupae were at levels comparable to normal (cf. also the footnote in Discussion). On the other hand, the weight of hatched larvae was affected by $100 \mu \mathrm{g}$ ecdysteroid given at day 2 of pupal stage (Table 1). 


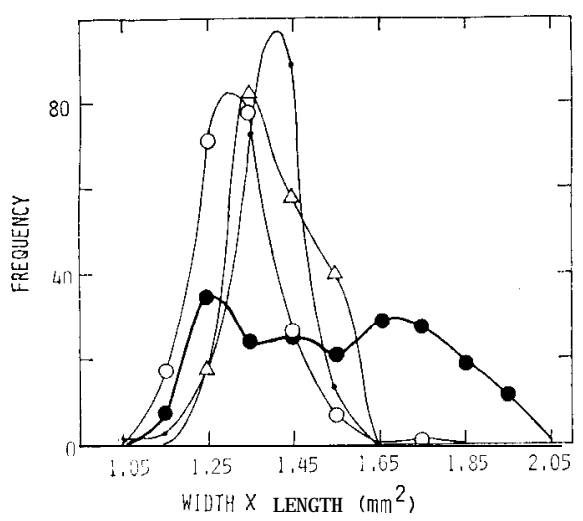

Fig. 6. Effects of 20-hydroxyecdysone (Ed) and C-18 juvenile hormone (JH) on the size distribution of deposited eggs. Pupae (N $122 \times$ C 115) received hormone as indicated below at day 2 (except for $P_{8}$ ) as mentioned in Fig. 1. Deposited eggs were measured for width $\times$ length (see Methods). For each analysis 200 eggs taken randomly out of a pool of eggs deposited by 20 moths were used. $\bullet, 10 \%$ ethanol (EtOH), peanut oil, normal, or $1 \mu \mathrm{g} \mathrm{Ed}$, $100 \mu \mathrm{g} \mathrm{Ed;} \triangle, \mathrm{P}_{8} 100 \mu \mathrm{g} \mathrm{Ed}$;, $10 \mu \mathrm{g} \mathrm{JH}$.

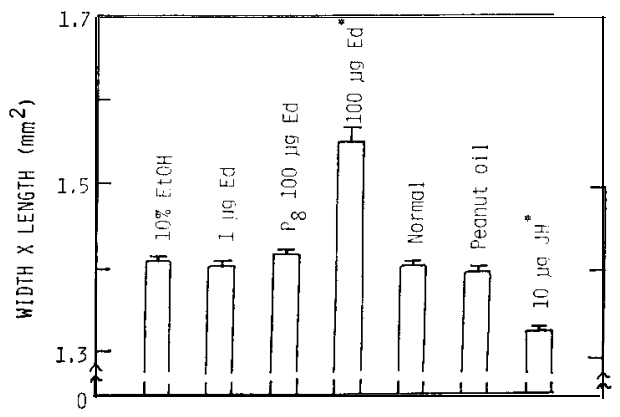

Fig. 7. Effects of 20-hydroxyecdysone (Ed) and C-18 juvenile hormone $(\mathrm{JH})$ on the mean size per egg. Data were arranged from Fig. 6. *, significant at $\mathrm{p}<0.01$ by the Kolmogorov-Smirnov test.

\section{I S C U S S I O N}

Our work shows that the developing silkworm pupae are resistant to large doses of ecdysteroid. Administration of $10 \mu \mathrm{g}$ of 20-hydroxyecdysone, probably lo-fold excess of the endogenous amount of ecdysteroid, did not disturb the time schedule of adult development. Only the animals met with 100 -fold excess of the hormone exhibited changes in period of emergence, but they seemed unchanged morphologically. The resistance of pupae to the exogenous hormone was also manifest in the reproduction system maturing during pupal stage. The eggs deposited from the animals thus treated with the 100 fold excess hormone could hatch, implying that the oogenesis and fertilization 
Table 1. Effects of 20-hydroxyecdysone (Ed) and C-18 juvenile hormone $(\mathrm{JH})$ on the weight of eggshells and larvae after hatching. Pupae (N 122 $\mathrm{xC124}$ ) were treated with above substances at day 2 (or 8) as mentioned in Fig. 1. For each measurement 500 hatched individuals and eggshell leftovers were taken randomly out of a pool of eggs deposited by 20 moths. They were air-dried and weighed. The average weight per shell or larva was calculated by division.

\begin{tabular}{|c|c|c|c|}
\hline \multirow{2}{*}{ Treatment } & \multicolumn{2}{|c|}{ Average weight of } & \multirow{2}{*}{$\begin{array}{c}\text { Hatched eggs } \\
\text { per total } \\
(\mathscr{O})\end{array}$} \\
\hline & \multicolumn{2}{|c|}{$(\mu \mathrm{g})$} & \\
\hline Normal & 62.9 & 147 & 94.4 \\
\hline $10 \%$ ethanol & 69.5 & 149 & 91.0 \\
\hline $1 \mu \mathrm{g} \mathrm{Ed}$ & 62.1 & 118 & 60.2 \\
\hline $100 \mu \mathrm{g} \mathrm{Ed}$ & 57.7 & 183 & 82. 8 \\
\hline $\mathrm{P}_{8} 100 \mu \mathrm{g} \mathrm{Ed}$ & 67.9 & 119 & 83.6 \\
\hline Peanut oil & 68.7 & 110 & 53.2 \\
\hline $10 \mu \mathrm{g} \mathrm{JH}$ & 67.1 & 99 & 74.8 \\
\hline
\end{tabular}

occurred normally. However, the 100- $\mu$ g hormone treatment lowered the increase in wet and dry weight of ovary during oogenesis. Interestingly, this lowering was finally offset by the extended period of oogenesis and this extension was warranted by the delay of adult emergence. The oocyte maturation might possibly be coordinated with eclosion, both being dependent upon ecdysteroid.

The eggs from the animals treated with the 100 -fold excess hormone showed hypertrophy in weight and size of eggs. The weight increase could not be ascribed to the chorion proteins (see Table 1), and thus to oocyte materials. In fact, newly hatched larvae derived from the animals that had been treated with 20-hydroxyecdysone at day 2 of pupal age were found to be heavier than control by more than $20 \%$ (Table 1 ). ${ }^{1}$ Yolk formation is stimulated by the exogenous ecdysteroid according to Takei et al. (1978) and Ono et al. (1975), and this, together with the elongation of oogenesis period, might cause the excess accumulation of yolk substances, which in turn explains the occurrence of hypertrophic larvae. It is possible to suppose that the high titre of ecdysteriod at the early pupal stage has a role in determining the extent of oocyte development. This inferrence is further supported by the fact that juvenile hormone, a possible antagonist of ecdysteroid, reduced the egg size and the period of oocyte maturation (Figs. 6 and 1). Based upon these arguments, we suggest that the ovary recovers from the artificial hy. perecdysonism by a simple way, an elongation of developmental time. This might be a mode of response of developing systems against perturbation.

The action of excess ecdysteroid presumably involves the following processes. (1) Promotion of some mechanisms responsible for catabolic processes of ecdysteroid. (2) Lowering the hormonal efficiency by the reduction of

1 Larger larvae must have ingested more of eggshells than normally sized larvae during hatching and measurements of eggshell weight after hatching in the former case may suffer from a more intense underestimation. 
their affinities for receptors. (3) Slow transmission of hormonal information to post-transcriptional levels, e.g. initiation processes of peptide synthesis (cf. Liao et al., 1975). Reseach work which should permit approach to any of the above possibilities will be of interest in relation to the mode of action of the steroid hormone.

\section{ACKNOWLEDGEMENTS}

We thank Mr. Masaki Nagashima at the Sericultural Experiment Station (Kyushu) for his kind supply of the silkworms.

\section{REFERENCES}

Ashburner, M. 1973 Sequential gene activation by ecdysone in polytene chromosomes of Drosophila melanogaster. 1. Dependence upon ecdysone concentration. Develop. Biol., 35: 47-61

Hanaoka, K. and E. Ohnishi 1974 Changes in ecdysone titre during pupal-adult development in the silkworm, Bombyx mori. J. Insect Physiol., 20: 2375-2384

Liao, S., J. L. Tymoczko, E. Castaneda, T. Liang 1975 Androgen receptors and androgendependent initiation of protein synthesis in the prostate. Vitam. Horm. N. Y., 33: 297-317

Mandaron, P. 1973 Effects of $\alpha$-ecdysone, $\beta$-ecdysone and inokosterone on the in vitro evagination of Drosophila leg discs and the subsequent differentiation of imaginal integumentary structures. Develop. Biol., 31: 101-113

Marks, E. P. 1970 The action of hormones in insect cell and organ culture. Gen. Comp. Endocrinol., 15 : 289-302

Ono, S., H. Nagayama and K. Shimura 1975 The occurrence and synthesis of femaleand egg-specific proteins in the silkworm, Bombyx mori. Insect Biochem., 5: 313-329

Takei, R., E. Nagashima and A. Kobayashi 1978 Effects of ecdysterone on oogenesis and hatching in Bombyx mori. Abstracts of Papers, 34th Meeting of Japanese Society of Sericultural Science, Chubu-branch, Ueda, Noveber, p. 26

Williams, C. M. 1968 Ecdysone and ecdysone-analogues: Their assay and action on diapausing pupae of the Cynthia silkworm. Biol. Bull., 134: 344-355 